\title{
O PENSAMENTO COMPUTACIONAL NO ENSINO FUNDAMENTAL I: Saberes Articulados entre Computação e Artes Visuais
}

\author{
Pietro Matheus Bompet Fontoura Alves ${ }^{1}$ \\ Pauleany Simões de Morais ${ }^{2}$ \\ Rejane de Oliveira Alves ${ }^{3}$
}

\section{RESUMO}

O presente artigo investiga as potencialidades do ensino de Computação com ênfase ao Pensamento Computacional articulado com Artes Visuais no Ensino Fundamental I. A atividade foi resultante do Estágio Supervisionado da Licenciatura em Computação, tendo a pesquisa-ação como metodologia norteadora e a Computação Desplugada como o conjunto de técnicas que possibilita as ações no contexto de uma escola pública de Salvador/BA. Os resultados apresentam a necessidade da presença da Computação na escola, especialmente articulada com os componentes curriculares já existentes. Ademais, a investigação demonstra que é possível desenvolver ações envolvendo o Pensamento Computacional articulado com outras áreas do conhecimento para além das Ciências Exatas.

Palavras-chave: Licenciatura em computação. Formação inicial de professores. Computação. Saberes.

COMPUTATIONAL THINKING IN ELEMENTARY SCHOOL:

\section{ARTICULATED KNOWLES BETWEEN COMPUTING AND VISUAL ARTS}

\section{ABSTRACT}

This article investigates the potential of teach Computer Science with an emphasis on Computational Thinking, articulated with Visual Arts in Elementary Education. The activities resulted from the Supervised Internship in Computer Science, with action research as a guiding methodology and Computer Science Unplugged, as the set of techniques that enabled actions in the context of a public school of Salvador/BA. The results show the need for the presence of Computing in the school, especially articulated with the existing curricular components. In addition, the investigation demonstrates that it's possible to develop actions involving Computational Thinking articulated with other areas of knowledge, in addition to Exact Sciences. Keywords: Degree in computing. Initial teacher training. Computing. Knowledge.

Recebido em: 30/11/2020

Aceito em: $5 / 2 / 2021$

\footnotetext{
1 Programa de Pós-graduação em Educação (PGEDU) - Faculdade de Educação (FACED) - Universidade Federal da Bahia (UFBA). Salvador/ BA, Brasil. http://lattes.cnpq.br/3935834525982637. http://orcid.org/0000-0002-8034-6014. pietrobompet@ufba.br.

2 Instituto Federal de Educação, Ciência e Tecnologia do Rio Grande do Norte (IFRN) e IFBA. Natal/RN e Salvador/BA, Brasil. http://lattes.cnpq. br/9701543756709612. https://orcid.org/0000-0001-5660-2746. pauleanysm@gmail.com

3 Autora correspondente. Universidade Federal da Bahia - Faculdade de Educação - Faced. Av. Reitor Miguel Camon, s/n., Vale do Canela. CEP 41110-100. Salvador/BA, Brasil. http://lattes.cnpq.br/0940477150933097. https://orcid.org/0000-0002-4632-0013. rejane.alves@ufba.br
} 
Ao longo dos anos, as discussões sobre o Pensamento Computacional (PC) revelam potenciais estratégias e contribuições para a aprendizagem dos educandos, envolvendo diversas áreas do conhecimento ao redor do mundo. De acordo com De CarvaIho, Chaimowicz e Moro (2013), destacam-se ações desenvolvidas na Educação Básica do Estado do Alabama nos Estados Unidos (EUA), bem como iniciativas de um projeto multidisciplinar entre professores de Computação e Língua Inglesa. No Brasil, iniciativas em diversas partes do país são comumente apresentadas em eventos acadêmico-científicos, com destaque para o Workshop de Informática na Escola (WIE) e o Simpósio Brasileiro de Informática na Educação (SBIE) (ZANINI; RAABE, 2012).

No que diz respeito ao Ensino da Computação, os estudos sobre o desenvolvimento do $\mathrm{PC}^{4}$ apresentam novas possibilidades de mobilizar o conhecimento por meio de práticas docentes em todos os graus de ensino. A pesquisadora americana Jeanette Wing (2006) discute, de forma pioneira, o termo Pensamento Computacional, ao se referir às diversas probabilidades analíticas da Ciência da Computação. Nesse contexto, justifica-se a relevância dos estudos dessa autora na fundamentação teórico-metodológica e análise dos resultados do trabalho. A dimensão conceitual, delimitada por Wing (2006), relaciona-se com o potencial da área diante da necessidade de desenvolvimento da Ciência da Computação, quando se destina à resolução de problemas, abstração, decomposição, automação, simulação, modelação, pensamento recursivo, sequencial e paralelo. Segundo a mesma autora (2006), as habilidades computacionais configuram-se como diferentes possibilidades para a resolução de problemas e contribuem para as novas leituras de mundo na construção do conhecimento.

Ao analisar os trabalhos publicados no Brasil que envolvem o Pensamento Computacional entre 2006 e 2019, Souza et al. (2019, p. 534) identificaram que o "ensino do PC ainda está muito voltado para sua aplicação na área de ciências exatas, ao invés de ser trabalhado numa proposta mais interdisciplinar". Apesar disso, constatam-se recorrentes publicações (OLIVEIRA et al., 2020; NUNES, 2011) a partir de vivências em instituições da Educação Básica da rede pública, nas quais licenciandos e professores de Computação desenvolvem estudos e ações com colegas professores atuantes nas diversas áreas do conhecimento já consolidadas no currículo escolar brasileiro. Apesar dos esforços, a abordagem e os desdobramentos dessa temática em conteúdos e componentes curriculares em outras áreas do conhecimento, ainda hoje não acontecem ou pouco são publicizados, concentrados em experiências pontuais de eventos acadêmicos, discutidos com pesquisas das mesmas comunidades científicas.

Justifica-se a relevância do Pensamento Computacional em razão das suas potencialidades em promover conexões de saberes entre a Computação e as demais áreas do conhecimento, de modo a promoverem ações voltadas ao Ensino da Computação na

\footnotetext{
“ Na área da Ciência da Computação existem discordâncias teóricas acerca do uso dos termos "pensamento" e "raciocínio" computacional. Optamos, no entanto, por empregar o termo "pensamento" por partilharmos da compreensão apresentada por Ferreira et al. (2015, p. 257), de que "o raciocínio computacional é utilizado de forma mais específica, quando o pensamento está relacionado ao pensamento analítico e ao raciocínio dedutivo que envolve a lógica e a matemática".
} 
Educação Básica. No estudo proposto neste artigo, os autores apresentam as contribuições das técnicas e conteúdos didáticos de Artes Visuais articulados com a Computação, desenvolvidos durante o Estágio Curricular Supervisionado.

Este estudo propõe-se a investigar as potencialidades do ensino de Computação com ênfase ao Pensamento Computacional, sugerindo conexões de saberes com Artes Visuais no 3 o ano do Ensino Fundamental da escola pública desenvolvido no segundo semestre letivo de 2018. O percurso metodológico que orientou o desenvolvimento da investigação foi a pesquisa-ação, por adequar-se à perspectiva de atuação em processos formativos que incidem sobre o ensino da Computação na escola pública. Na condução dos encaminhamentos metodológicos da atividade em sala de aula, a partir do desenvolvimento do ciclo vital da pesquisa-ação - planejar, agir, descrever e avaliar (TRIPP, 2005) -, utilizou-se uma abordagem construtivista e integrada ao conjunto de técnicas da Computação Desplugada (BELL; WITTEN; FELLOWS, 2009). A partir do exposto foi construída uma sequência didática que contemplasse conteúdos da área específica do professor em formação e conteúdos/elementos provenientes de, ao menos, um componente curricular presente no currículo da Educação Básica, que, neste projeto, voltou-se à área da Arte.

O componente curricular Artes Visuais foi escolhido para a construção e o desenvolvimento das atividades em decorrência da escassez de produção científica na literatura, bem como a matriz curricular em vigência na Educação Básica já contemplar o componente durante a formação no Ensino Fundamental I e II. O curso de Licenciatura em Computação possibilita aos egressos a articulação de saberes entre as diversas áreas do conhecimento, sendo originário da interseção de três grandes áreas (Ciência da Computação, Educação e Matemática). É constituído a partir da natureza plural e interdisciplinar, em decorrência de o mesmo apresentar "[...] grande potencial com relação à produção de materiais didáticos e científicos especializados para o ensino de Computação na Educação Básica, bem como os demais estudos que centram-se na área de TDIC [Tecnologias Digitais da Informação e Comunicação] e Educação" (OLIVEIRA et al., 2020, p. 3), assim como vivenciam a necessidade do desenvolvimento de práticas e formações para além das Ciências Exatas (SOUZA et al., 2019).

Nosso enfoque em torno do Pensamento Computacional permitiu o diálogo com autores como: Bompet e Morais (2020), Bompet e Alves (2019), Imbernón (2016), Paiva et al. (2017), Scaico et al. (2012) e Souza, Morais e Silva Júnior (2015) acerca da formação inicial de professores; Araújo et al. (2015), Brackmann (2017), Ferreira et al. (2015), França et al. (2014), Nunes (2011), Oliveira et al. (2020), Pereira, Araújo e Bittencourt (2019) e Souza et al. (2019) sobre ensino de Computação na Educação Básica.

Para fim de sistematização do material produzido e aquele a ser apresentado neste artigo, os autores deste estudo destacaram uma atividade realizada, sistematizada por etapas, em turmas do 2으 e 3 o anos do Ensino Fundamental, com alunos/as entre seis e nove anos. O material utilizado para a produção da atividade veio, exclusivamente, de recursos já encontrados no contexto escolar e de baixo valor econômico, como lápis coloridos, canetas esferográficas e hidrocores. 
A partir disso, o presente artigo analisa as potencialidades do ensino de Computação, com ênfase ao Pensamento Computacional, articulado ao componente curricular de Artes Visuais do Ensino Fundamental I. As etapas da atividade de Computação foram integradas aos conteúdos presentes na matriz curricular do componente Artes Visuais, com atuação do professor de Computação em formação.

Este artigo está organizado nas seguintes seções: a primeira seção contempla uma breve reflexão sobre os estudos e atividade prática envolvendo o pensamento computacional; a segunda apresenta a experiência formativa na escola do licenciando em Computação por meio da sistematização da atividade Desplugada, desenvolvida no Ensino Fundamental I; e, por último, os autores tecem considerações sobre a relevância da experiência como possibilidade do ensino da Computação na Educação Básica.

\section{O PENSAMENTO COMPUTACIONAL E O ENSINO DA COMPUTAÇÃO DESPLUGADA NA ESCOLA PÚBLICA}

Com intenso potencial de articular ações, discussões e debates entre as áreas do conhecimento (FERREIRA et al., 2015; PEREIRA; ARAÚJO; BITTENCOURT, 2019; FRANÇA et al., 2014), nota-se a presença da temática do pensamento computacional nos processos educacionais orientadores da prática docente em Ciência da Computação. Tais processos implicam um planejamento pedagógico e técnico que envolve conhecimentos científicos, pedagógicos, didáticos, metodológicos e conceituais na sistematização dos conhecimentos científicos próprios da Ciência da Computação e da apropriação orientada da Tecnologia Educacional.

Para o desenvolvimento da atividade voltado ao ensino da computação, é necessário compreender, de maneira mais ampla, que, a partir de um "ambiente comunicativo didático, as aulas deveriam gerar múltiplas situações de comunicação e de uso tanto da linguagem oral e escrita como dos diversos códigos de relação interpessoal, a partir dos níveis, registros e códigos dos próprios alunos" (IMBERNÓN, 2016, p. 83). É necessário construir práticas pedagógicas articuladas aos conteúdos e componentes curriculares presentes nos currículos, com especial valorização das produções dos sujeitos envolvidos, a fim de evitar o processo de fragmentação curricular.

A ausência de tópicos articulados e/ou conteúdos curriculares específicos da Computação no currículo da Educação Básica brasileira, incompreensões acerca do papel do profissional licenciando/licenciado em Computação na sociedade, formação e ressignificação da identidade docente, e a escassez de espaços formais e não formais de Educação que acolham os professores em formação e permitam o desenvolvimento de práticas e pesquisas, são fatores que se configuram como os principais desafios contemporâneos na formação dos licenciandos em Computação nos cursos em atividade no Brasil (PAIVA et al., 2017; SOUZA; MORAIS; SILVA JÚNIOR, 2015).

Na busca por práticas que contemplem os conteúdos, instrumentos/procedimentos didáticos específicos da Computação, foram realizadas atividades que envolviam o Pensamento Computacional, pois apresentam-se como promissoras na abordagem inicial de temáticas da área, seja na Educação Básica ou em cursos de formação inicial e continuada. A aprendizagem, desenvolvida por meio das habilidades necessárias à 
Computação, particularmente pela programação, pode estimular na criança o potencial "[...] de articular o trabalho de sua própria mente e, particularmente, a interação entre ela e a realidade no decurso da aprendizagem e do pensamento" (PAPERT, 1971, p. 3).

Em sua tese, Brackmann (2017) apresenta os quatros pilares necessários ao desenvolvimento do pensamento computacional, apresentados a seguir: a decomposição, o reconhecimento de padrões, a abstração e os algoritmos. O primeiro refere-se à identificação de um problema e em dividi-lo em unidades menores e mais viáveis de se gerenciar, sendo reconhecido como o processo de Decomposição. Seguindo, cada uma dessas sequências menores seria percebida individualmente com maior intensidade, reduzindo, assim, a complexidade no momento de resolvê-los. Ao final, as unidades solucionadas poderiam ser novamente agrupadas, processo esse denominado de Composição. Nesse contexto, pode-se identificar elementos e/ou características semelhantes solucionadas em outras situações-problemas por meio do Reconhecimento de Padrões. A habilidade, denominada Abstração, significa atentar-se aos detalhes significativos, em que as informações irrelevantes são desconsideradas e os Algoritmos representam passos ou regras simples que conduziram para solucionar os subproblemas identificados (BRACKMANN, 2017). Como Wing (2006), o referido autor considera que o pensamento computacional é necessário a qualquer sujeito, independentemente de sua área de conhecimento ou atividade profissional, como ler, escrever ou mesmo calcular.

Diante desses estudos, a vivência, a partir da conexão de saberes entre as áreas do conhecimento, pode concretizar-se como elemento potencializador do ensino da Computação, uma vez que essa característica busca romper com a linearidade do conhecimento e promover articulações entre este conhecimento e os sujeitos-aprendentes (BOMPET; ALVES, 2019). A conexão de saberes auxilia a concepção do conhecimento de maneira mais ampla em realidades concretas, internalizadas de forma significativa e integrada para a melhoria da leitura de mundo. Para além de denominações presentes na literatura em referência à articulação dos conhecimentos (inter, multi, pluri ou transdisciplinaridade), os autores desta pesquisa voltam-se para o estudo e o desenvolvimento de práticas contextualizadas e comprometidas com as aprendizagens significativas dos sujeitos-participantes da pesquisa.

Segundo os professores Bompet e Alves (2019), a escola configura-se como espaço para o fomento das experiências e dos aprendizados, da mesma maneira que se apresenta repleta de tensões e desafios para os sujeitos envolvidos. Aos licenciandos presentes no espaço escolar são necessárias permanentes ressignificações no processo de constituição do ser docente e, consequentemente, na construção/afirmação das suas identidades profissionais.

A escola, sendo um dos principais campos desses profissionais é marcada por tensões e dilemas, tais como a afirmação da profissão escolhida, transformações das posturas no exercício da docência e ressignificações da constituição da identidade que podem até provocar a crise da identidade docente (BOMPET; ALVES, 2019, p. 10-11).

Ao analisar a infraestrutura da escola pública da rede municipal de Salvador/BA, parceira do projeto de estágio, optou-se por desenvolver a atividade utilizando a Computação Desplugada, sendo ela uma abordagem destinada ao desenvolvimento do ra- 
ciocínio lógico dos envolvidos sem o uso dos computadores (SOUSA et al., 2011), além de possibilitar, segundo Scaico et al. (2012, p. 4), que os alunos "[...] aprendem como os computadores fazem para resolver problemas e aplicam técnicas, através de uma abordagem problematizadora e orientada a desafios, para resolver situações do cotidiano". Essa abordagem ainda favorece o emprego de recursos variados, sendo eles não tecnológicos, para auxiliar os alunos a compreenderem conteúdos referentes à área de Computação, mas não se restringe a ela.

O ensino na Educação Básica, conforme exposto por Araújo et al. (2015, p. 2), "caminha a passos lentos" em razão da ausência histórica da Computação na Educação pública, bem como expõe a necessidade de maiores oportunidades para o desenvolvimento da formação profissional docente do professor de Computação e suas práticas pedagógicas, tendo em vista o avanço das tecnologias em todos os setores da sociedade. Por isso, neste trabalho ressalta-se a importância da atuação do licenciado em Computação enquanto professor em formação. Esse apresenta-se como articulador dos conhecimentos que precisam ser sistematizados para o desenvolvimento da Computação e do Pensamento Computacional na escola pública, e por sua matriz curricular ser de caráter interdisciplinar, torna-se possível a articulação com as demais áreas do conhecimento. Especialmente nesta investigação, os estudos voltaram-se para a integração da referida área com Artes Visuais, essa raramente retratada nos eventos, periódicos, dissertações e teses em articulação com a Ciência da Computação.

No contexto brasileiro, Araújo, Andrade e Guerrero (2016) realizaram um mapeamento dos estudos que envolvessem o pensamento computacional nas práticas de ensino. Os mesmos autores constataram que existem diversos relatos acerca de práticas/ atividades inspiradas a partir das técnicas da Computação Desplugada (SOUSA et al., 2011) que favorecem o ensino da Computação sem necessidade de utilização de recursos digitais. Nesse sentido, a atividade foi desenvolvida a partir de numa perspectiva de conexão de saberes e apresenta como referência o emprego de materiais concretos já existentes na escola com destaque para desenvolvimento de conceitos e práticas da Computação e Artes Visuais.

A partir do exposto, buscou-se desenvolver atividade que rompessem com qualquer possibilidade de "fragmentação das ciências e dos conhecimentos produzidos por elas e onde simultaneamente se exprime a resistência sobre um saber parcelado" (THIESEN, 2008, p. 547). A perspectiva de conexão de saberes, portanto, embasa este estudo, permitindo aos sujeitos envolvidos a busca necessária à produção e à socialização do conhecimento.

Utilizou-se a Computação Desplugada, sendo esse um conjunto de técnicas que consiste no ensino dos fundamentos da Computação sem o uso do computador, visando a extinguir as barreiras técnicas de apreensão da ciência (VIEIRA; PASSOS; BARRETO, 2013). Diante de uma abordagem construtivista, Solé (2006, p. 41) argumenta que "tudo contribui para formar uma imagem do outro que pode ser reforçada ou totalmente modificada pela experiência cotidiana". Nesse sentido, o objetivo primordial do emprego da Computação Desplugada foi promover a construção de conteúdos e práticas de aprendizagem mais próximas da realidade dos sujeitos, especialmente aqueles/as provenientes da Ciência da Computação. 


\section{O ENSINO DA COMPUTAÇÃO E AS VIVÊNCIAS DE UM PROFESSOR EM FORMAÇÃO NA ESCOLA PÚBLICA}

Como já descrevemos anteriormente, o lócus da pesquisa foi uma escola pública da rede municipal de Educação de Salvador/BA no 3ㅇa ano do Ensino Fundamental I e, mais especificamente, com uma professora-supervisora da área de Artes Visuais. A atividade a ser apresentada neste trabalho foi concebida a partir de reuniões e planejamento conjunto com a docente citada e a coordenação pedagógica, com enfoque na Computação Desplugada. Para isso, estudamos, planejamos e ressignificamos a atividade que envolveu conteúdo específicos da área de atuação da professora-supervisora na escola, com a participação de duas turmas de 3o ano do Ensino Fundamental (40 alunos).

Os conteúdos provenientes das áreas do conhecimento abordadas na atividade são detalhados a seguir: para a Computação, os raciocínios computacionais da abstração, decomposição e reconhecimento de padrões foram trabalhados, e, em relação à área de Artes Visuais, a composição das cores primárias, secundárias e terciárias, bem como a utilização de técnicas de pintura com traços finos, foram incorporadas às tarefas.

Deste modo, iniciamos com a atividade de pintura, para a qual foram usados os seguintes materiais: papel A4, pincéis atômicos, lápis de cor, gizes de cera e canetas hidrográficas. Destaca-se que, para fins de estudos e práticas futuras, tendo como referência a atividade descrita, todos os materiais empregados são acessíveis e de baixo custo, sendo disponibilizados, inclusive, pela própria escola pública. O conteúdo proposto é encontrado no segundo ciclo do calendário letivo para a área de Artes Visuais já presente no planejamento pedagógico elaborado junto a professora-supervisora.

A mesma atividade foi subdividida em duas etapas: a primeira compreendia a identificação das cores primárias e a formação das cores secundárias; já a segunda contemplou a pintura do desenho entregue somente com cores secundárias, sendo elas formadas pela junção das cores primárias reservadas usadas na etapa anterior. Em toda a atividade foram desenvolvidos os raciocínios computacionais (Abstração, Composição e Decomposição de Padrões), juntamente com as cores primárias e secundárias, conteúdo proveniente da área de Artes Visuais, com ênfase nas habilidades relatadas nos estudos de Wing (2006) e Brackmann (2017), elencadas anteriormente no referencial teórico.

Para realizarem a primeira etapa, os alunos receberam a imagem de uma flor impressa em preto e com as pétalas vazadas na cor branca, representada pela Figura 1 (à esquerda). Ao mesmo tempo, foram entregues um conjunto composto por lápis de cor e gizes de cera com variadas cores e tons, incluindo as cores primárias (vermelho, amarelo e azul), e apresentado um exemplo de pintura utilizando somente as cores primárias na composição. A mesma figura traz a descrição exemplificada do uso das cores em cada pétala, sinalizadas pelas cores secundárias. 
Figura 1 - Desenho original da atividade (à esquerda) e exemplo de pintura (à direita)
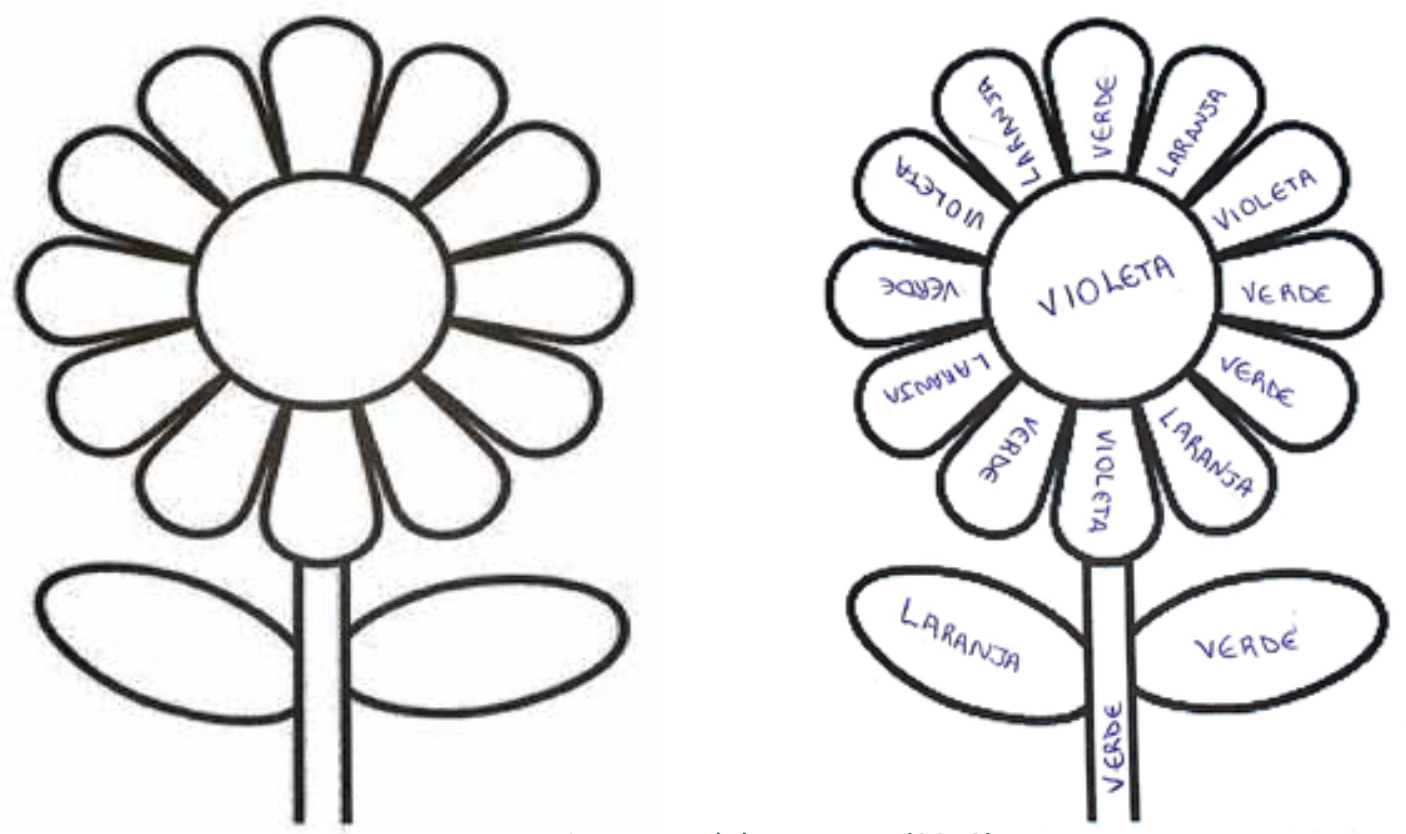

Fonte: Arquivo pessoal dos autores (2018).

Em posse dos materiais, cada educando deveria separar as referidas cores primárias, reservando as demais cores não utilizadas. Nesse ponto, a Abstração se fez presente no processo de escolha das cores, exigindo do educando a atribuição de prioridades para a escolha das três cores primárias em detrimento de todas as outras (WING, 2006; BRACKMANN, 2017). Essa habilidade permite a compreensão das estratégias adotadas pelos sujeitos para a realização das etapas previstas e resolução das situações-problemas de acordo com os objetivos traçados. Independentemente da ordem inicial de escolha da cor, o educando deveria ter como objeto primordial de reflexão os resultados das uniões de cores para a construção das cores secundárias. Após a identificação das cores e suas integrações, permitindo, assim, a geração de novas cores, os educandos puderam articular a habilidade de Reconhecimento de Padrões ao estabelecerem quais materiais faziam parte de cada grupo de cores (primárias e secundárias).

Logo em seguida, foi apresentado para a turma o esquema de composição das cores (Figura 2), de modo a representar um exemplo de união das cores primárias para a formação das cores secundárias (verde, violeta e laranja). A explicação ainda contemplou a possibilidade de intercâmbio das cores primárias na etapa de união, sendo discutidas com a turma todas as possibilidades de combinação. Na atividade houve a vivência das habilidades necessárias ao desenvolvimento do pensamento computacional, em que a abstração se fez presente no momento da escolha de elementos primordiais para a composição e a integração das etapas, bem como a definição de objetivos, organizados em etapas, para a concretude do propósito (WING, 2006; BRACKMANN, 2017). 
Figura 2 - Esquema de composição das cores secundárias a partir das primárias

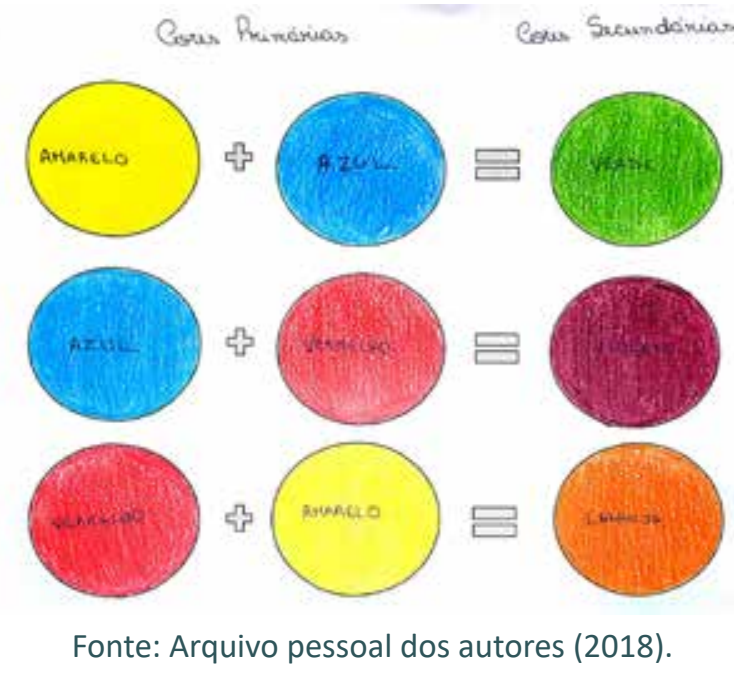

A partir disso, os alunos deveriam colorir seus desenhos individualmente com cores secundárias, sendo elas formadas pela união de duas cores primárias. Durante a início da atividade, notou-se que os alunos selecionavam uma única cor e preenchiam a metade de cada pétala escolhida, trocando a cor somente ao final de uma determinada quantidade de espaços preenchidos. Essa ação foi concretizada a partir da "divisão em etapas" da mesma tarefa, caracterizando-se, assim, como o processo de decomposição do problema (WING, 2006; BRACKMANN, 2017).

Após isso, os alunos repetiam o processo até que todos os espaços estivessem coloridos com, pelo menos, uma cor, e, depois, elegeram uma cor diferente para unir com esta e formar a cor secundária, caracterizando o desenvolvimento da habilidade de Reconhecimento de Padrões. A Figura 3 representa o método de sistematização da pintura pelos alunos participantes.

Figura 3 - Interpretação do método de resolução da atividade pelos alunos participantes

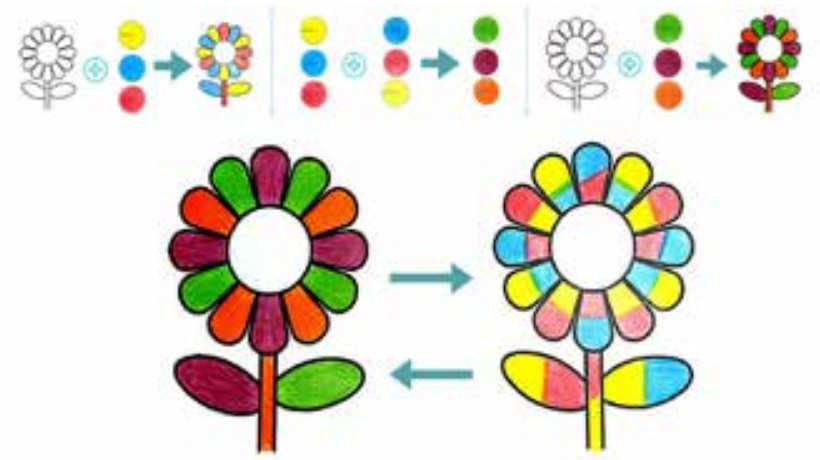

Fonte: Arquivo pessoal dos autores (2018).

Destaca-se que a existência de lápis de cor com tons variados das cores, especialmente a respeito das cores primárias, configurou-se um elemento de complexidade para a escolha dos alunos, necessitando que o licenciando explicasse que o objetivo da atividade era o preenchimento das pétalas da figura com as devidas cores primárias, e que o tom delas não se configurava como característica importante. A Figura 4 apresenta algumas produções dos alunos. 
Figura 4 - Produções dos alunos do 1으 ano do Ensino Fundamental
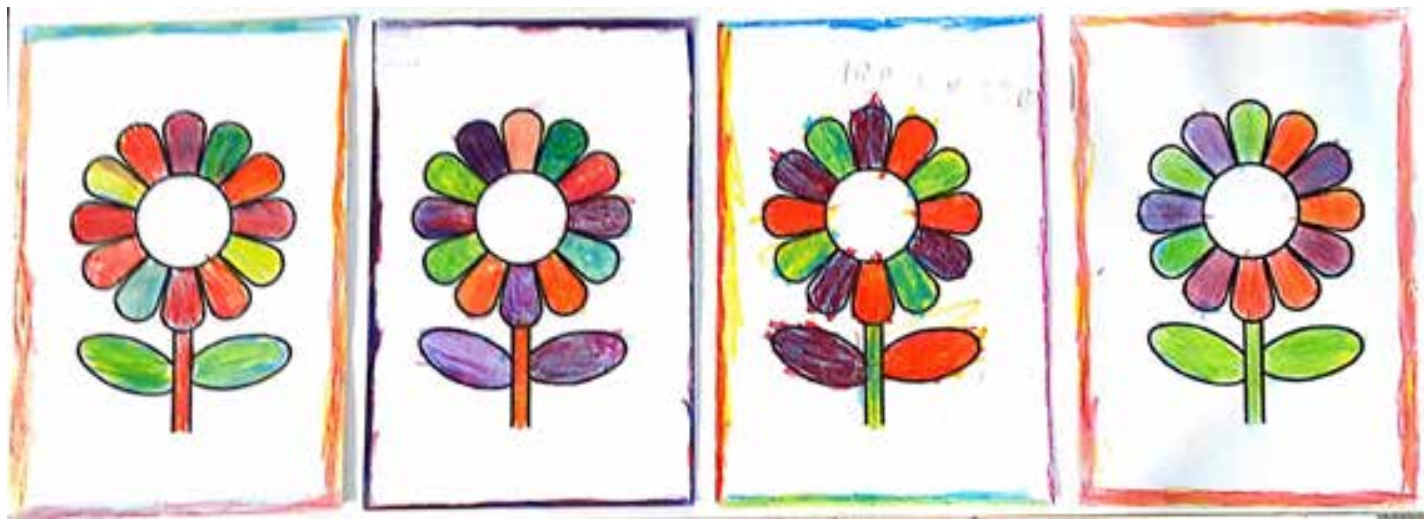

Fonte: Arquivo pessoal dos autores (2018).

No que se refere aos pilares do pensamento computacional trabalhados na atividade, dentre eles a abstração, o reconhecimento de padrões, a composição e a decomposição, notou-se que os estudantes conseguiram alcançar os objetivos didáticos por meio da utilização das habilidades computacionais integradas às etapas das tarefas. Durante o processo de definição das cores na atividade, a habilidade da Abstração constitui-se como elemento primordial para a definição das combinações possíveis e coerentes para atender o objetivo proposto. Para além disso, a Composição e a Decomposição ocorreram no ato de definição dos subgrupos de cores (Primárias e Secundárias).

Diante disso, a atividade descrita neste artigo apresenta possibilidades para o desenvolvimento do PC por meio de ações articuladas da Computação com componentes curriculares já presentes no currículo da Educação Básica, com especial atenção ao Ensino Fundamental I. Cabe ressaltar acerca da importância do professor de Computação em formação que, durante a pesquisa, vivenciou o cotidiano da instituição escolar, construindo e adequando o planejamento pedagógico de acordo com o tempo e as necessidades da turma participante da investigação. Vale salientar que houve outras atividades no transcurso do estágio curricular da Licenciatura em Computação, no entanto elencamos essa específica para análise por compreender as especificidades e relevância de cada etapa no desenvolvimento das habilidades.

\section{CONSIDERAÇÕES FINAIS}

A contribuição da Computação para a Educação, especialmente considerando a temática do Pensamento Computacional e seus raciocínios trabalhados na atividade descrita, configurou-se como temática amplamente abordada e igualmente publicizada a partir de 2006. Apesar disso, é necessário ressaltar que ainda hoje há poucos trabaIhos publicados com notória articulação da Computação para além de si própria e/ou das Ciências Exatas na literatura, com repercussões na concretude real dos ambientes educacionais públicos, nos quais as pesquisas e atividades são desenvolvidas. Ainda a partir desse contexto, é importante a participação de professores de Computação em formação em todas as etapas do desenvolvimento científico das pesquisas, desde a concepção do projeto, ida para escola e desenvolvimento das ações e atuação permanente na produção de materiais didáticos-pedagógicos e de divulgação científica. 
A vivência promovida por meio da atividade permitiu a articulação de saberes da Computação e Artes Visuais em situações concretas na escola pública. Além disso, a construção de saberes foi principalmente mediada pela trajetória acadêmica de formação na Licenciatura em Computação e a iniciação da docência em situações reais de ensino e aprendizagem. Os conteúdos da Computação foram desenvolvidos e transpostos para a realidade dos anos escolares assistidos, tendo como princípio o desenvolvimento de ações que utilizassem também os conhecimentos advindos de Artes Visuais. Dessa maneira, estabeleceram-se mobilizações de saberes plurais, dotados da integração entre as áreas.

Além disso, o professor em formação vivenciou experiências profícuas a partir da compreensão da realidade escolar, tendo em vista que a inserção dos licenciandos em Computação nos contextos educacionais é limitada e, por vezes, incompreendida/inexistente, pois os profissionais em atuação da Educação ainda não compreendem o papel deste profissional, minimizando-o às tarefas de ordem técnica e operacionais da Tecnologia da Informação.

Somente com o acesso à realidade escolar o professor de Computação em formação tem a oportunidade de integrar-se na relação gestão-professor-aluno-comunidade, bem como na construção do planejamento didático-pedagógico por meio da sistematização de conhecimentos contextualizados, vivenciando o tempo-espaço escolar, diferentemente do que é experienciado nos ambientes acadêmicos apenas com estudos teóricos.

De modo geral, compreender o papel da Computação na Educação Básica em busca de novos sentidos, de modo a possibilitar que os sujeitos participantes conheçam os fundamentos e conteúdos inerentes à área - mesmo que nos anos iniciais da sua formação docente - e a prática vivenciada no contexto escolar, contribuiu para ressignificações na prática docente do professor de Computação em formação e, igualmente, na formação do professor pesquisador, mesmo no âmbito da Graduação.

A formulação de práticas que envolvessem a Computação Desplugada possibilitou que a atividade realizada não dependesse de infraestruturas tecnológicas ou recursos computacionais, elementos escassos em âmbitos escolares das unidades da rede municipal de Educação de Salvador/BA. Quando existem, esses mesmos recursos são restritos à gestão e coordenação das escolas. Essa característica da Computação Desplugada permite que atividades já existentes possam ser praticadas em múltiplos espaços educativos, além de serem criadas outras novas para quaisquer públicos e contextos da realidade educacional.

A conquista pelo espaço na escola, bem como a confiança dos sujeitos envolvidos (a professora-supervisora, os educandos presentes nas turmas, coordenação e gestão escolar), também se configurou como fator determinante para o desenvolvimento das ações. As práticas in loco possibilitaram um marco histórico-curricular do ensino da Computação naquela realidade escolar em virtude da experiência inovadora e, até então desconhecida, da existência da área com o fomento de práticas na Educação Básica.

Por fim, os autores desta investigação ressaltam que a vivência na escola, sem as referências curriculares e profissionais, comprometem a conquista de espaços condizentes e necessárias para a formação inicial docente do professor de Computação. Essa 
vivência exige do licenciando em formação na escola autonomia e criatividade para a elaboração da atividade e o desenvolvimento das ações didático-pedagógicas em seu estágio. Apesar disso, o professor em formação vivencia experiências da prática educativa na busca da constituição dos saberes pedagógicos com a interação dos estudos teóricos do ensino da Computação e o fomento da práxis necessária à futura atuação docente.

\section{REFERÊNCIAS}

ARAUJO, Ana Liz; ANDRADE, Wilkerson; GUERRERO, Dalton. Um mapeamento sistemático sobre a avaliação do pensamento computacional no brasil. In: WORKSHOPS DO CONGRESSO BRASILEIRO DE INFORMÁTICA NA EDUCAÇÃO, 2016. Anais [...]. 2016. p. 1.147. Disponível em: https://br-ie.org/pub/index.php/ wcbie/article/view/7040. Acesso em: 30 nov. 2020.

ARAÚJO, Débora da Conceição; RODRIGUES, Ariane; ARAÚJO SILVA, Cláudia; SOARES, Leonardo. O ensino de computação na educação básica apoiado por problemas: práticas de licenciandos em computação. In: WORKSHOP SOBRE EDUCAÇÃO EM COMPUTAÇÃO 23., 2015. Anais [...]. Porto Alegre: SBC, 2015. p. 130-139. BELL, Tim; WITTEN, Ian; FELLOWS, Mike. Computer science unplugged: school students doing real computing without computers. The New Zealand Journal of Applied Computing and Information Technology, 13(1), p. 20-29, 2009.

BOMPET, Pietro; ALVES, Rejane. Ressignificações da identidade docente na formação inicial de professores/as: saberes e fazeres na licenciatura. In: COLÓQUIO INTERNACIONAL EDUCAÇÃO E CONTEMPORANEIDADE, 13., 2019. São Cristóvão, 2019. Disponível em: https://ri.ufs.br/bitstream/riufs/13180/37/36.pdf. Acesso em: 29 jun. 2020.

BOMPET, Pietro; MORAIS, Pauleany. O professor de computação em formação: experiências de conexões de saberes nos anos iniciais do Ensino Fundamental. In: CONGRESSO SOBRE TECNOLOGIAS NA EDUCAÇÃO, 5., 2020. Anais [...]. Porto Alegre: SBC, 2020. p. 356-364.

BRACKMANN, Christian Puhlmann. Desenvolvimento do pensamento computacional através de atividades desplugadas na educação básica. 2017. 226 f. Tese (Doutorado) - Universidade Federal do Rio Grande do Sul, Informática na Educação, Cinted, Porto Alegre, 2017.

DE CARVALHO, Márcio Luiz Bunte; CHAIMOWICZ, Luiz; MORO, Mirella M. Pensamento computacional no Ensino Médio Mineiro. In: CONGRESSO DA SOCIEDADE BRASILEIRA DE COMPUTAÇÃO (CSBC), 33.; WEI WORKSHOP SOBRE EDUCAÇÃO EM COMPUTAÇÃO, 2013. Anais [...]. Maceió, AL, 2013.

IMBERNÓN, Francisco. Qualidade do ensino e formação do professorado: uma mudança necessária. Tradução Silvana Cobucci Leite. São Paulo: Cortez, 2016.

FERREIRA, Ana Carolina Cerqueira; MELHOR, André; BARRETO, Jandiaci; PAIVA, Luiz Fernando de; MATOS, Ecivaldo. Experiência prática interdisciplinar do raciocínio computacional em atividades de computação desplugada na Educação Básica. CONGRESSO BRASILEIRO DE INFORMÁTICA NA EDUCAÇÃO, 4., CONFERÊNCIA LATINO-AMERICANA DE OBJETOS E TECNOLOGIAS DE APRENDIZAGEM (CBIE-LACLO), 10., WORKSHOP DE INFORMÁTICA NA ESCOLA, 21., 2015. Maceió. Anais [...]. Maceió/AL, 2015.

FRANÇA, Rozelma Soares de; FERREIRA, Victor Afonso dos Santos; ALMEIDA, Luma Cardoso Ferro de; AMARAL, Haroldo José Costa. A disseminação do pensamento computacional na educação básica: lições aprendidas com experiências de licenciandos em computação. In: WORKSHOP SOBRE EDUCAÇÃO EM COMPUTAÇÃO, 22., 2014. Anais [...]. Brasília: SBC, 2014. p. 219-228. Disponível em: https://sol.sbc.org. br/index.php/wei/article/view/10976. Acesso em: 30 nov. 2020.

NUNES, Daltro. Ciência da computação na educação básica. 2011. Jornal do Sindicato Intermunicipal dos Professores de Instituições Federais de Ensino Superior do Rio Grande do Sul - ADUFRGS SINDICAL. Disponível em: https://adufrgs.org.br/artigos/ciencia-da-computacao-na-educacao-basica/. Acesso em: 30 nov. 2020.

OLIVEIRA, Wilk; FRANÇA, Rozelma; LEMOS, André; DA CRUZ, Marcia Kniphoff; SCAICO, Pasqueline; AMARAL, Haroldo; TEIXEIRA, Lilian Pereira. Os desafios enfrentados pela licenciatura em computação que a comunidade de educação em computação precisa conhecer. In: WORKSHOP SOBRE EDUCAÇÃO EM COMPUTAÇÃO (WEI), 28., 2020. Cuiabá. Anais [...]. Porto Alegre: Sociedade Brasileira de Computação, 2020. p. 191-195. ISSN 2595-6175. DOI: https://doi.org/10.5753/wei.2020.11156. 
PAIVA, Luiz Fernando; BOMPET, Pietro; CORLETT, Emilayne Feitosa; MATOS, Ecivaldo; SCHWARZELMULLER, Anna Friedericka. A formação, o trabalho e a identidade profissional do professor de computação: um mapeamento sobre a Licenciatura em computação. In: CONGRESSO BRASILEIRO DE INFORMÁTICA NA EDUCAÇÃO, 6., Recife, v. VI, p. 893-901, 2017. Disponível em: org.crossref.xschema._1.Title@41f68938 PAPERT, Seymour. Teaching Children Thinking. Logo Memo no 2, 1971. Disponível em: https://archive.org/ details/bitsavers_mitaiaimAl_471587. Acesso em: 15 jun. 2020.

PEREIRA, Francisco Tito Silva Santos; ARAÚJO, Luís Gustavo; BITTENCOURT, Roberto. Intervenções de pensamento computacional na educação básica através de computação desplugada. In: WORKSHOP DE INFORMÁTICA NA ESCOLA, 2019. Anais [...]. p. 315. Disponível em: https://br-ie.org/pub/index.php/wie/ article/view/8518. Acesso em: 30 nov. 2020. Doi: http://dx.doi.org/10.5753/cbie.wie.2019.315.

SCAICO, Pasqueline; HENRIQUE, Mychelline; CUNHA, Felipe; DE ALENCAR; Yugo. Um relato de experiências de estagiários da licenciatura em computação com o ensino de computação para crianças. Renote Revista Novas Tecnologias na Educação, v. 10, n. 3, 2012.

SOLÉ, Isabel. Disponibilidade para a aprendizagem e sentido da aprendizagem. In: COLL, César et al. $O$ construtivismo na sala de aula. 6. ed. 8. imp. São Paulo, SP: Editora Ática, 2006.

SOUZA, Fabiula; LEITE, Ramon; BRITO, Cecy Maria; VILLELA, Maria; SANTOS, Carolina Queiroz. O desenvolvimento do pensamento computacional além do ensino em ciências exatas: uma revisão da literatura. In: BRAZILIAN SYMPOSIUM ON COMPUTERS IN EDUCATION (SIMPÓSIO BRASILEIRO DE INFORMÁTICA NA EDUCAÇÃO - SBIE), 30(1), p. 528, 2019. DOI: http://dx.doi.org/10.5753/cbie.sbie.2019.528

SOUZA, Odair; MORAIS, Pauleany; SILVA JÚNIOR, Francisco Silva. Um estudo sobre a evasão no curso de Licenciatura em Informática do IFRN - Campus Natal - Zona Norte. In: WORKSHOP SOBRE EDUCAÇÃO EM COMPUTAÇÃO (WEI), 23., SBC, 2015, p. 216-225.

SOUSA, Raniere Viana de; BARRETO, Luciano Porto; ANDRADE, Aline. ABDALLA, Débora. Ensinando ciência da computação sem o uso do computador. Computer Science Unplugged ORG, 2011. Disponível em: https://classic.csunplugged.org/wp-content/uploads/2014/12/CSUnpluggedTeachers-portuguese-brazil-feb-2011.pdf. Acesso em: 4 jul. 2020.

THIESEN, Juares da Silva. A interdisciplinaridade como um movimento articulador no processo ensino-aprendizagem. Revista Brasileira de Educação [online], v. 13, n. 39, p. 545-554, 2008.

TRIPP, David. Pesquisa-ação: uma introdução metodológica. Educação e Investigação, São Paulo, v. 31, n. 3, p. 443-466, set./dez. 2005.

VIEIRA, Anacilia; PASSOS, Odette; BARRETO, Raimundo. Um relato de experiência do uso da técnica computação desplugada. In: CONGRESSO DA SOCIEDADE BRASILEIRA DE COMPUTAÇÃO, 33., 2013. Porto Alegre. Anais [...]. Porto Alegre: Sociedade Brasileira de Computação, 2013. p. 671-680.

WING, Jeannete Marie. Computational thinking. Communications of the Acm, 49(3), p. 33-35, 2006.

ZANINI, Adriana Salvador; RAABE, André Luís Alice. Análise dos enunciados utilizados nos problemas de programação introdutória em cursos de Ciência da Computação no Brasil. In: WEI - WORKSHOP SOBRE EDUCAÇÃO EM COMPUTAÇÃO, 20., CONGRESSO DA SOCIEDADE BRASILEIRA DE COMPUTAÇÃO, 30., 2012. Curitiba: SBC. p. 100-110. V. 1. 